\title{
Hydroxyflutamide enhances cellular sensitivity to 5-fluorouracil by suppressing thymidylate synthase expression in bicalutamide- resistant human prostate cancer cells
}

\author{
RUMI KAWABATA ${ }^{1,2}$, SHINJI OIE ${ }^{2}$, TOSHINORI OKA ${ }^{2}$, MASAYUKI TAKAHASHI ${ }^{3}$, \\ HIROOMI KANAYAMA ${ }^{3}$ and KOHJI ITOH ${ }^{1}$ \\ ${ }^{1}$ Graduate School of Pharmaceutical Sciences, The University of Tokushima; ${ }^{2}$ Tokushima Research Center, \\ Taiho Pharmaceutical Co., Ltd.; ${ }^{3}$ Department of Urology, Institute of Health Biosciences, \\ The University of Tokushima Graduate School, Tokushima, Japan
}

Received October 19, 2010; Accepted December 1, 2010

DOI: 10.3892/ijo.2011.909

\begin{abstract}
We investigated the antitumor effects of combination therapy with anti-androgens and 5-fluorouracil (5-FU), and examined the underlying mechanism of the treatment. Initially, we established the bicalutamide-resistant subline CDX25R from the androgen receptor (AR)-positive human prostate cancer cell line LNCaP through continuous exposure to bicalutamide. CDX25R cells lost the ability to respond to androgens, but still expressed AR. They showed significant resistance to bicalutamide, but had high sensitivity to hydroxyflutamide (OH-flutamide) compared with LNCaP cells. The CDX25R subline was thus considered to be a suitable model for prostate cancer that has developed resistance to first-line hormonal therapy but shows sensitivity to an alternative approach. Combined treatment with 5-FU and $\mathrm{OH}$-flutamide had a synergistic effect on CDX25R cells. OH-flutamide decreased expression of the transcription factor E2F1, and subsequently of thymidylate synthase (TS), in CDX25R cells but not in AR-negative DU145 cells. This suggested that $\mathrm{OH}$-flutamide enhanced the growth-inhibitory activity of 5-FU in CDX25R cells by reducing TS expression through the AR pathway. Combined therapy with 5-FU and OH-flutamide may, therefore, be appropriate for patients with prostate cancer that has acquired resistance to initial hormone therapy including bicalutamide.
\end{abstract}

\section{Introduction}

Prostate cancer is a major health issue and is ranked as the second leading cause of cancer among men worldwide

Correspondence to: Dr Rumi Kawabata, Tokushima Research Center, Taiho Phermaceutical Co., Ltd., 224-2 Ebisuno, Hiraishi, Kawauchi-cho, Tokushima, Japan

E-mail: rumi-kawabata@taiho.co.jp

Key words: anti-androgen, E2F1, 5-fluorouracil, prostate cancer, thymidylate synthase
(American Cancer Society 2007 Prostate Cancer Statistics; http://www.cancer.org). In the United States, it is estimated that 217,730 men will be diagnosed with prostate cancer and that 32,050 deaths from this disease will occur during 2010 (American Society of Clinical Oncology Prostate Cancer Statistics; http://www.cancer.net/prostate).

Hormonal therapy, such as androgen-deprivation therapy, has previously been used to treat prostate cancer. Androgen deprivation can be achieved surgically by castration, or chemically by suppressing androgen production using luteinizing hormone-releasing hormone (LH-RH) agonists. Bicalutamide $\left(\right.$ Casodex $\left.{ }^{\circledR}\right)$ and flutamide (Odyne $\left.{ }^{\circledR}\right)$ are non-steroidal competitive antagonists of androgen receptors (ARs), which are able to block the androgen-dependent cell growth of prostate cancer. Anti-androgen administration combined with surgical or medical castration, known as maximal androgen blockade (MAB) or combined androgen blockade (CAB), can slightly but significantly improve the survival rates of patients with prostate cancer $(1,2)$.

Most prostate cancers are responsive to initial hormonal therapy, but subsequently relapse and become androgen-independent within a few years of first-line treatment (3). Despite this unwelcome progression to androgen-independence, the usefulness of alternative, second-line MAB therapy has been reported by several investigators (4-6). The main options currently available for hormone-refractory prostate cancer (HRPC) are second-line hormonal manipulations, radiation therapy, traditional cytotoxic chemotherapy and investigational therapy with novel and molecular-targeted agents $(7,8)$. Tannock et al demonstrated that treatment with docetaxel, a microtubule-stabilizing agent, plus prednisone improved survival, with a median survival advantage of 2.4 months compared to mitoxantrone plus prednisone, for advanced prostate cancer (9). Petrylak et al reported that docetaxel and estramustine improved survival, with a median survival advantage of 1.9 months compared to mitoxantrone and prednisone, for advanced refractory prostate cancer (10). However, increased toxicity has been reported for these docetaxel-based combination therapies $(9,10)$. More effective but less toxic combined therapy is therefore required for HRPC patients. 


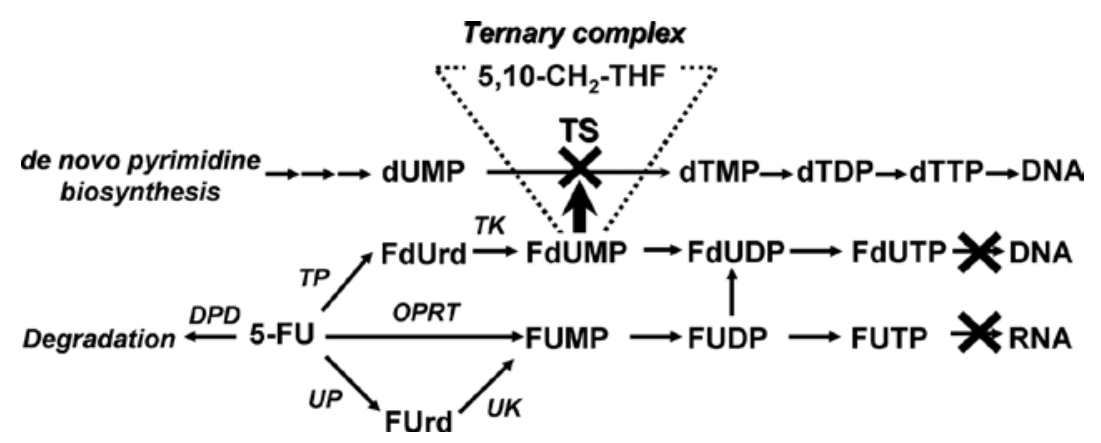

Figure 1. Schematic representation of the 5-FU metabolic pathway. In sequential reactions, 5-FU is converted to 5-fluoro-2'-deoxyuridine (FdUrd) by TP, and then to FdUMP by TK. FdUMP inhibits TS activity by forming a covalent ternary complex with TS and 5,10-methylenetetrahydrofolate (5,10-CH2-THF) and consequently limits DNA synthesis. FdUMP is also converted to FdUTP and incorporated into DNA, which disrupts normal DNA function. 5-FU is also converted to FUTP in sequential reactions, with the conversion of 5-FU to 5-fluorouridine (FUrd) catalyzed by UP, the conversion of FUrd to FUMP by UK or the conversion of 5-FU to FUMP by OPRT. FUTP is then incorporated into RNA, which disrupts normal RNA function. DPD decomposes 5-FU into an inactive metabolite. These enzymes might thus be closely associated with sensitivity to 5-FU.

5-Fluorouracil (5-FU) is an effective chemotherapeutic drug that was developed as an inhibitor of thymidylate synthetase (TS). Inhibition of TS leads to 'thymine-less death' in cells, which is a condition resulting from the depletion of dTTP pools and the misincorporation of dUTP into newly synthesized or repaired DNA (11). 5-FU is also incorporated into RNA, and RNA-based effects play a significant role in its cytotoxicity (11). The sensitivity of cancer cells to 5-FU is often influenced by the expression levels of the target enzyme TS and the metabolic enzymes for 5-FU, including thymidine phosphorylase (TP), dihydropyrimidine dehydrogenase (DPD), orotate phosphoribosyl transferase (OPRT), uridine phosphorylase (UP), uridine kinase (UK) and thymidine kinase (TK) (12-14). The expression of selected elements of the 5-FU metabolic pathway (Fig. 1) is predictive of the response to 5-FU-based chemotherapy regimens, and lower levels of TS, TP and DPD correlate with higher sensitivity to 5-FU (12). However, the association of cellular levels of these enzymes with sensitivity to 5-FU is controversial.

TS is a key enzyme in the de novo synthesis of thymidine, and is an important chemotherapeutic target for various malignant tumors. It catalyzes the transfer of a methyl group from methyltetrahydrofolate to dUMP in order to generate dTMP (15). The subsequent phosphorylation of dTMP to dTTP provides a direct precursor for DNA synthesis. Increased TS expression occurs in highly proliferative cells, and this is associated with poor treatment response and prognosis in a broad range of tumors (16). Increased TS protein and messenger RNA (mRNA) levels have been reported in prostate, cervical, breast, kidney, bladder, lung and gastrointestinal tumor tissues compared with their normal counterparts, and are associated with poor clinical outcome in these cancers (17-23). Among patients with prostate cancer undergoing radical prostatectomy or hormonal therapy, those with low TS expression had a longer postoperative recurrence-free period than those with high TS expression during a 5-year follow-up, suggesting that TS could be a prognostic marker (24). Tumors with elevated TS levels are thought to undergo more progressive cellular proliferation, which in turn is thought to be associated with tumor invasiveness and metastasis $(19,20,25)$. Therefore, TS is considered to be a molecular target for cancer therapy.
In the current study, we examined the combined antitumor activity of anti-androgens and 5-FU, and investigated the mechanism underlying this combination therapy using a newly established bicalutamide-resistant cell line.

\section{Materials and methods}

Reagents. Bicalutamide and 5-FU were obtained from SigmaAldrich (St. Louis, MO). OH-flutamide was obtained from LKT Laboratories Inc. (St. Paul, MN). Dihydrotestosterone (DHT) was obtained from Wako Pure Chemical Industries, Ltd. (Osaka, Japan). Testosterone was obtained from Tokyo Chemical Industry Co., Ltd. (Tokyo, Japan). 5-FU, bicalutamide and $\mathrm{OH}$-flutamide were dissolved in dimethyl sulfoxide (DMSO). DHT and testosterone were dissolved in ethanol.

Cell lines and culture. The androgen-dependent human prostate cancer cell line LNCaP and the androgen-independent human prostate cancer cell line DU145 were purchased from the American Type Culture Collection (ATCC, Rockville, MD), and cultured in RPMI-1640 (Sigma-Aldrich) supplemented with $10 \%$ fetal bovine serum (FBS) (Nichirei Corp., Tokyo, Japan) or in phenol red-free RPMI-1640 (SigmaAldrich) supplemented with $10 \%$ dextran charcoal-stripped FBS (csFBS) (Hyclone Laboratories, Inc., Logan, UT). CDX25R cells were developed by culturing LNCaP cells in phenol red-free RPMI-1640 supplemented with $10 \%$ csFBS in the presence of $25 \mu \mathrm{M}$ bicalutamide for 6 months.

Cell proliferation assay. Cells were incubated for 6 days in RPMI-1640 with $10 \%$ FBS containing $10 \mu \mathrm{M}$ bicalutamide. The medium was exchanged on day 3 , at which time fresh drugs were added. Cell proliferation was assessed by the crystal violet dye-uptake assay method (26) and absorbance measured at $540 \mathrm{~nm}$ using a 96-well microplate reader (SpectraMax 340PC384; Molecular Devices, Inc., Sunnyvale, CA).

Cell toxicity assay. Cells were incubated for 6 days in RPMI-1640 with 10\% FBS containing $3.2 \mu \mathrm{M}$ bicalutamide, $0.9 \mu \mathrm{M} \mathrm{OH}$-flutamide and/or $1.6 \mu \mathrm{M}$ 5-FU. The respective 
final concentrations of bicalutamide, flutamide and 5-FU were equivalent to the maximum blood concentration of each drug when the clinical dosage recommended in Japan was singly administered. The medium was exchanged on day 3 , at which time fresh drugs were added. The cell number was estimated by the crystal violet dye-uptake assay method on day 6 .

Androgen-dependency assay. Cells were incubated for 4 days in phenol red-free RPMI-1640 with $10 \%$ csFBS containing DHT or testosterone at $0.1,1$ or $10 \mathrm{nM}$. The relative cell number was estimated by the crystal violet dye-uptake assay method on day 4 , and was calculated compared to treatment with a solvent control (ethanol).

Western blot analysis. After washing with ice-cold phosphatebuffered saline (PBS), cells were harvested in protein extraction reagent $\left(\mathrm{M}-\mathrm{PER}^{\mathrm{TM}}\right.$; Pierce, Rockford, IL) supplemented with protease inhibitors (Halt ${ }^{\mathrm{TM}}$ protease inhibitor cocktail kit; Pierce). Cell lysates were subjected to sodium dodecyl sulfate polyacrylamide gel electrophoresis (SDS-PAGE) and transferred to polyvinylidene fluoride (PVDF) membranes (Immobilon-P transfer membranes; Millipore, Bedford, MA). After blocking, membranes were probed with primary antibodies overnight at $4^{\circ} \mathrm{C}$. Anti-TS antibody was a gift from the Taiho Pharmaceutical Co., Ltd., Japan. Anti-AR (441) antibodies were obtained from Santa Cruz Biotechnology (Santa Cruz, CA). Anti-E2F1, anti-phosphor-Rb [Ser750(4H1)], anti-Akt [pan(C67E7)], antip-Akt [Ser473(D9E), Thr308(C31E5)], anti-p-cRaf (Ser259), anti-p-PTEN (Ser380), anti-p-PDK1 [Ser241(C49H2)] and anti-p-GSK3b [Ser9(5B3)] antibodies were obtained from Cell Signaling Technology (Beverly, MA). Anti-prostatespecific antigen (PSA) (ER-PR8) and anti- $\beta$-actin antibodies were obtained from Abcam (Cambridge, UK). The proteins were visualized using horseradish peroxidase-conjugated secondary antibodies (Cell Signaling Technology) for $1 \mathrm{~h}$ at room temperature followed by enhanced chemiluminescence (Pierce). The intensity of luminescence was quantified using a charge-coupled device (CCD) camera combined with an image analysis system (LAS-3000; Fuji Film, Japan).

Complementary DNA (cDNA) preparation and real-time quantitative reverse-transcription polymerase chain reaction ( $q R T-P C R)$. The expression levels of the 5-FU-related genes thymidylate synthase (TS), DPD, OPRT, TP, TK, UP and UK were assessed in AR-positive (LNCaP and CDX25R) cells and AR-negative (DU145) cells treated with bicalutamide or $\mathrm{OH}$-flutamide at 5, 25 or $100 \mu \mathrm{M}$ for $24 \mathrm{~h}$, using real-time qRT-PCR. Total RNA was extracted by the RNeasy mini kit (Qiagen, Hilden, Germany) and reverse transcribed using a High Capacity cDNA Reverse Transcription kit (Life Technologies, Inc., Carlsbad, CA) according to the manufacturer's instructions. Two-step TaqMan real-time qRT-PCR was performed with an ABI PRISM 7900 (Life Technologies). The reactions were performed at $50^{\circ} \mathrm{C}$ for $2 \mathrm{~min}$, and at $95^{\circ} \mathrm{C}$ for $10 \mathrm{~min}$, followed by 40 cycles of $95^{\circ} \mathrm{C}$ for $15 \mathrm{sec}$ and $60^{\circ} \mathrm{C}$ for $1 \mathrm{~min}$. The results were normalized to $\beta$-actin levels. Primers and TaqMan probes for TS, DPD, OPRT, TP, TK, UP, UK and $\beta$-actin were prepared using the TaqMan Gene Expression Assay products Hs00426591_m1, Hs00559278_ m1, Hs00923517_m1, Hs00157317_m1, Hs01062125_m1,
Hs01066247_m1, Hs00367072_m1 and Hs99999903_m1, respectively (Life Technologies).

Assay for TS activity. TS activity in LNCaP and CDX25R cells treated with bicalutamide or $\mathrm{OH}$-flutamide at 5, 25 or $100 \mu \mathrm{M}$ for $48 \mathrm{~h}$ was assessed using a [6-3H] FdUMP binding assay based on the method of Spears et al (27).

Knock-down experiment with TS small-interfering RNA (siRNA). LNCaP and CDX25R cells were transfected with TS siRNA (TYMS-HSS187282; Life Technologies) or negative control siRNA in which the nucleotide sequence of TS siRNA was scrambled using lipofectamine RNAiMAX (Life Technologies), and then plated in RPMI-1640 with 10\% FBS and incubated overnight. On the following day, medium containing serially diluted 5-FU (final concentration range, 0.125-64 $\mu \mathrm{M}$ ) was added to the wells and cultured for a further 6 days. The medium was exchanged on day 3 , at which time fresh drugs were added. The relative cell number was estimated by the crystal violet dye-uptake assay method on day 6 , and the $\mathrm{IC}_{50}$ value (defined here as the 5-FU concentration that reduced the cell growth to $50 \%$ of that of the control) was calculated in comparison to solvent (DMSO) treatment.

Statistical analysis. mRNA expression, relative cell numbers and TS activity were analyzed using either the Student's t-test or the Dunnett's t-test with JMP ${ }^{\circledR}$ 8.0.1. software (SAS Institute Inc., Cary, NC).

\section{Results}

Establishment of a bicalutamide-resistant prostate cancer cell line. The bicalutamide-resistant CDX25R sub-cell line was produced from LNCaP cells by continuous exposure to $25 \mu \mathrm{M}$ bicalutamide in phenol red-free RPMI-1640 supplemented with $10 \%$ csFBS for at least 6 months. To confirm resistance to bicalutamide, its growth-inhibitory effects were tested on both CDX25R and LNCaP cells. Cell proliferation curves over 6 days with or without $10 \mu \mathrm{M}$ bicalutamide are shown in Fig. 2A. The growth rate of LNCaP cells treated with $10 \mu \mathrm{M}$ bicalutamide was inhibited compared with that of control cells on day 4 after the start of culture, and the cell number on day 6 was significantly reduced to $40 \%$ of that of the solvent control. However, the proliferation of CDX25R cells was not affected by bicalutamide. It was therefore clear that the CDX25R cells had acquired resistance to bicalutamide.

The LNCaP cells grew in clusters, whereas the CDX25R cells produced a monolayer (Fig. 2B). The CDX25R cells appeared to have undergone morphological changes that led them to resemble neuroendocrine cells differing from $\mathrm{LNCaP}$ cells. We next examined whether mutations of the AR gene spontaneously occurred in CDX25R cells. No AR mutations were present except for T877A, which is known to occur in the parental LNCaP cell line (data not shown). We were unable to establish an $\mathrm{OH}$-flutamide-resistant cell line from LNCaP cells by continuous exposure to the drug (data not shown).

Androgen-dependency of LNCAP and CDX25R cell proliferation. LNCaP and CDX25R cells were exposed to DHT or testosterone at concentrations of $0,0.1,1$ or $10 \mathrm{nM}$ for 4 days. 
$\mathbf{A}$ $\mathrm{LNCaP}$

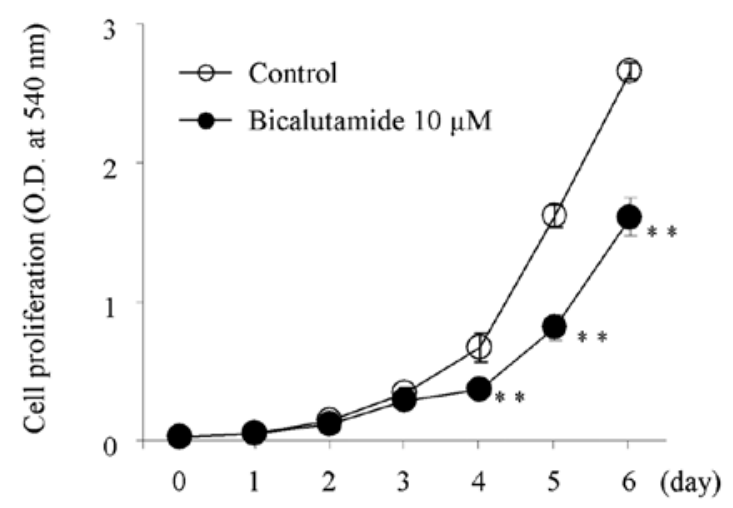

B

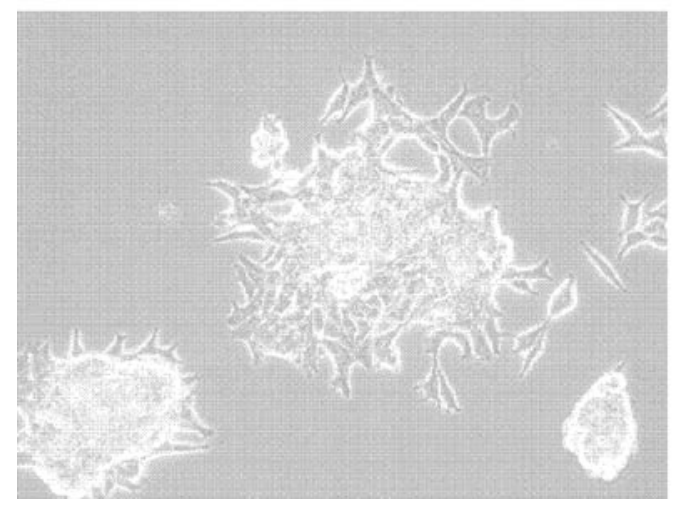

C

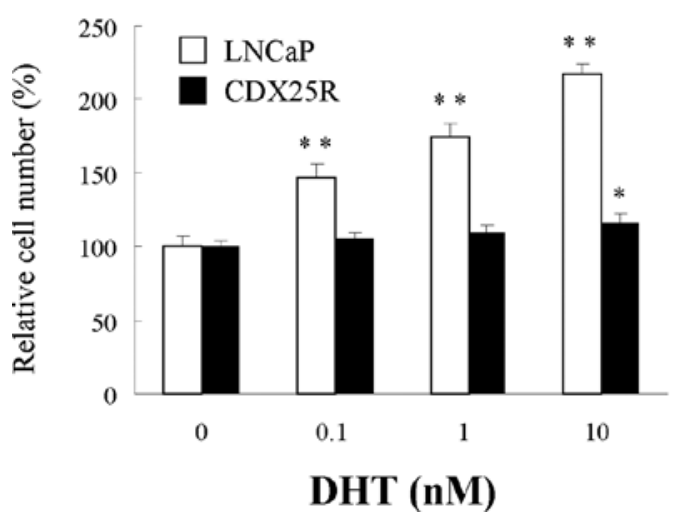

\section{CDX25R}

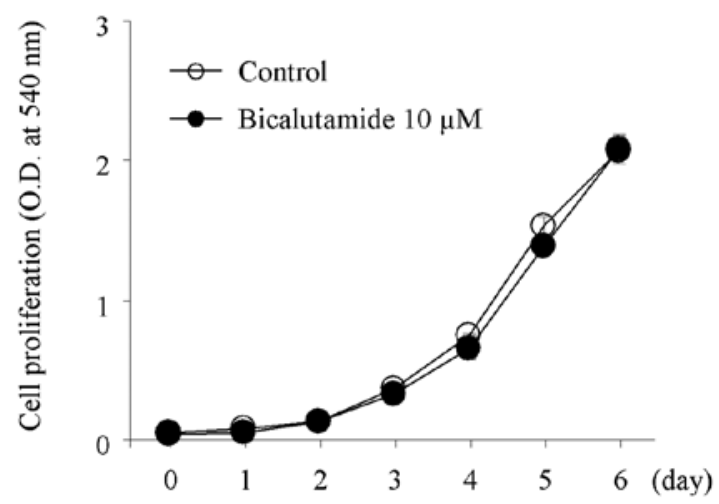

CDX25R
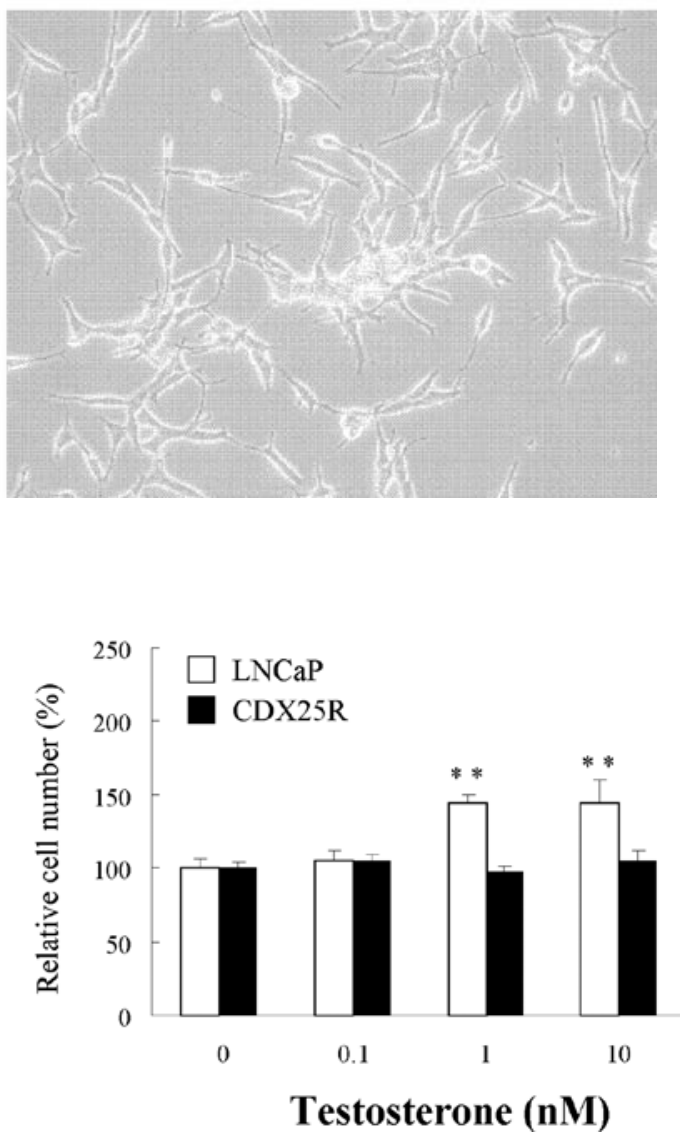

Figure 2. Characterization of bicalutamide-resistant CDX25R cell line. (A) Susceptibility of LNCaP and CDX25R cells to bicalutamide. Cells (1000 per well of a 96-well plate) were incubated in RPMI-1640 medium supplemented with $10 \%$ FBS for 24 h, then treated with or without $10 \mu$ M bicalutamide for 6 days. The cell number was estimated using the crystal violet dye-uptake method. Statistical analysis was performed by the Student's t-test. Significant differences from the control are shown as ${ }^{* *} \mathrm{p}<0.01$. (B) Morphology of LNCaP and CDX25R cells. Cells were grown in a 100-mm culture dish in RPMI-1640 medium supplemented with $10 \%$ FBS or csFBS. Cell images were visualized using photomicroscopy. (C) Androgen-dependency of proliferation of LNCaP and CDX25R cells. Cells (1000 per well of a 96-well plate) were incubated in phenol red-free RPMI-1640 supplemented with $10 \%$ csFBS for 24 h, then treated with $0,0.1,1$ or $10 \mathrm{nM}$ DHT or testosterone for 4 days. The cell number was estimated by the crystal violet dye-uptake method, and the cell number relative to the solvent control was calculated. Statistical analysis was performed by the Student's t-test. Significant differences from the control are shown as * $<<0.05$ and ${ }^{* *} \mathrm{p}<0.01$.

The relative cell numbers treated with each concentration of DHT or testosterone compared to control cells not exposed to the respective androgen are shown in Fig. 2C. DHT and testosterone enhanced the proliferation of LNCaP cells, but not CDX25R cells, in a dose-dependent manner. These results showed that CDX25R cells had lost their androgendependency.

Mechanism of androgen-independent CDX25R cell proliferation. Protein expression levels of AR and PSA in CDX25R 
D

$\mathrm{LNCaP}$

DHT (nM)

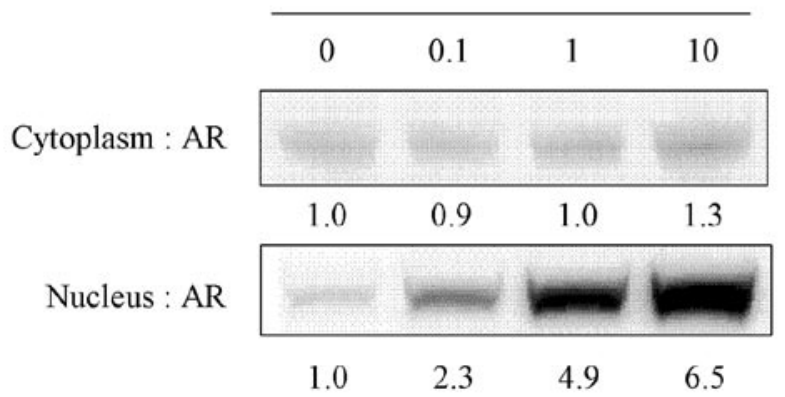

CDX25R

DHT (nM)

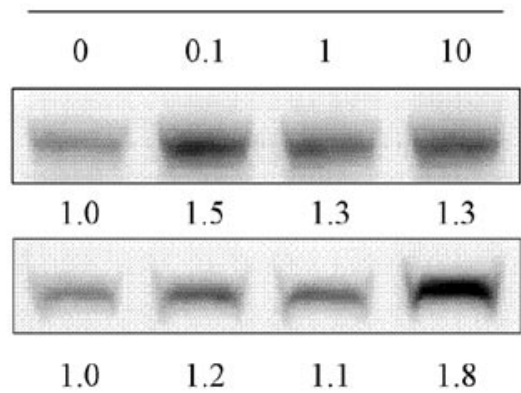

$\mathbf{E}$

\section{LNCaP CDX25R}

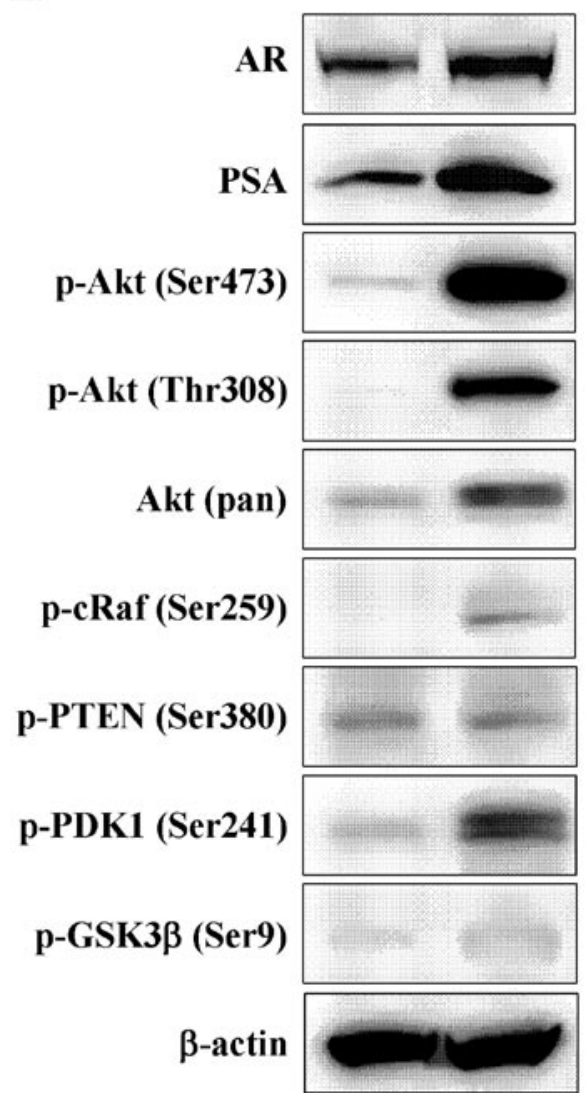

and LNCaP cells were determined. CDX25R cells expressed AR and PSA at levels two and three times higher, respectively, than LNCaP cells (Fig. 2E), although their growth was not dependent on androgens (Fig. 2C). To examine whether this androgen system functions in CDX25R cells, we focused on the nuclear translocation of AR. Protein expression levels of AR in the cytoplasm and nucleus of cells treated with or without DHT were measured by Western blotting. The nuclear translocation of AR was notably decreased in CDX25R cells compared with LNCaP cells (Fig. 2D). In CDX25R cells, although endogenous AR was overexpressed it tended to remain in the cytoplasm, even after exposure to high doses of DHT. These results suggested that the AR axis in CDX25R cells was inactivated.
Figure 2. (D) Translocation of AR to the nucleus in LNCaP and CDX25R cells. Cells $(40,000)$ were incubated in phenol red-free RPMI-1640 supplemented with $10 \%$ csFBS for $24 \mathrm{~h}$, then treated with $0,0.1,1$ or $10 \mathrm{nM}$ DHT for $24 \mathrm{~h}$. The cytoplasmic and nuclear protein fractions were extracted separately, and analyzed by immunoblotting ( $50 \mu \mathrm{g} / \mathrm{lane})$, followed by image analysis. The numbers below the immunoblots represent the band intensity compared with that of the solvent control, which was taken as 1.0. (E) Protein expression of AR, PSA and Akt axis-related factors in LNCaP and CDX25R cells. Cells were incubated in RPMI-1640 supplemented with $10 \%$ FBS for 3 days. Cell lysates ( $33 \mu \mathrm{g} /$ lane) were analyzed by immunoblotting.

To investigate the existence of AR-bypass pathways, the Akt (pan), p-Akt (Ser473), p-Akt (Thr308), p-cRaf (Ser259), p-PTEN (Ser380), p-PDK1 (Ser241), p-GSK3 $\beta$ (Ser9) and $\beta$-actin protein expression levels in LNCaP and CDX25R cells were assessed by Western blotting. CDX25R cells overexpressed p-PDK1, Akt (pan), p-Akt (Ser473) and p-Akt (Thr308) compared with LNCaP cells (Fig. 2E). 5-FU (2.5-20 $\mu \mathrm{M})$ had no effect on Akt-axis protein expression in either CDX25R or LNCaP cells (data not shown). These results suggested that the CDX25R cells had lost androgen dependency, although AR was still expressed, because the AR/androgen axis did not function. It appeared that the CDX25R cells had begun to grow through the Akt axis, because they overexpressed p-Akt.

Antiproliferative effects of 5-FU combined with bicalutamide or OH-flutamide. The growth-inhibitory effects of 5-FU combined with bicalutamide or $\mathrm{OH}$-flutamide were examined in $\mathrm{LNCaP}$, CDX25R and DU145 cells (Fig. 3). LNCaP, CDX25R and DU145 cells were treated with 5-FU and bicalutamide or $\mathrm{OH}$-flutamide for 6 days, and the cell number was subsequently estimated by the crystal violet dye-uptake method. 5-FU slightly inhibited the growth of LNCaP cells [the relative cell number defined as the ratio of the cell number in the drug-treated group $(\mathrm{T})$ to that in the non-drug-treated control group (C) was 92.2\%] and bicalutamide inhibited cell growth by about $20 \%$. Combined treatment of $5-\mathrm{FU}$ and bicalutamide reduced the cell growth to about $50 \%$ compared with non-treated control cells (Fig. 3A).

$\mathrm{OH}$-flutamide showed no effect on the growth of LNCaP cells, but the growth-inhibitory activity of 5-FU was enhanced from 8 to $35 \%$ when it was co-administered with $\mathrm{OH}$-flutamide (Fig. 3D). By contrast, bicalutamide showed no growth-inhibitory activity in CDX25R cells, and only slightly enhanced the activity of 5-FU (Fig. 3B). Notably, OH-flutamide had a significant growth-inhibitory effect $(\mathrm{T} / \mathrm{C}=50 \%)$ in $\mathrm{CDX} 25 \mathrm{R}$ cells, 
A

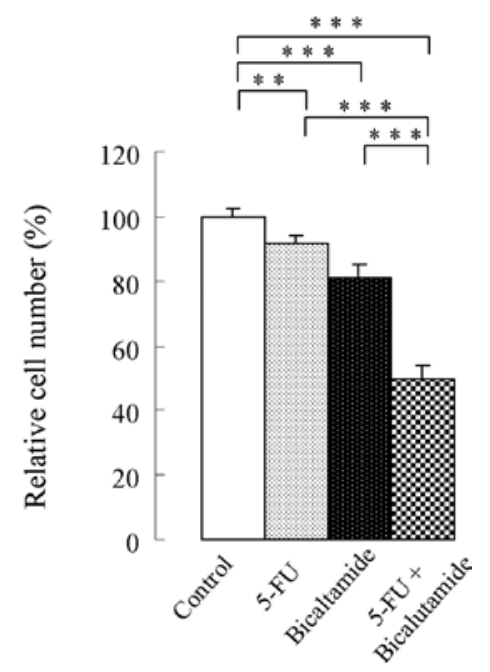

B

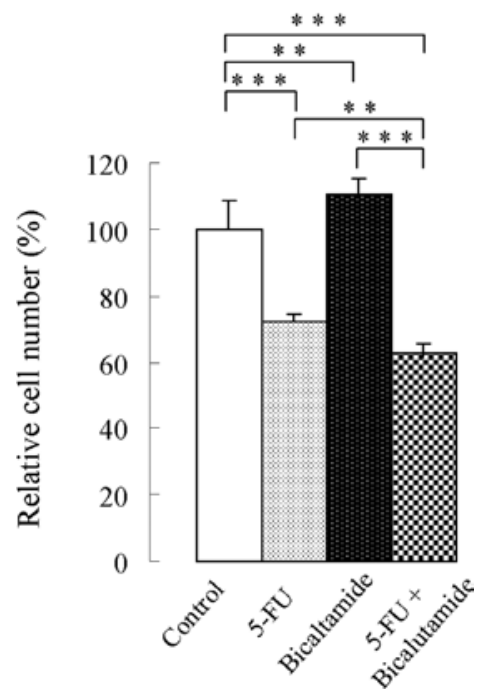

C

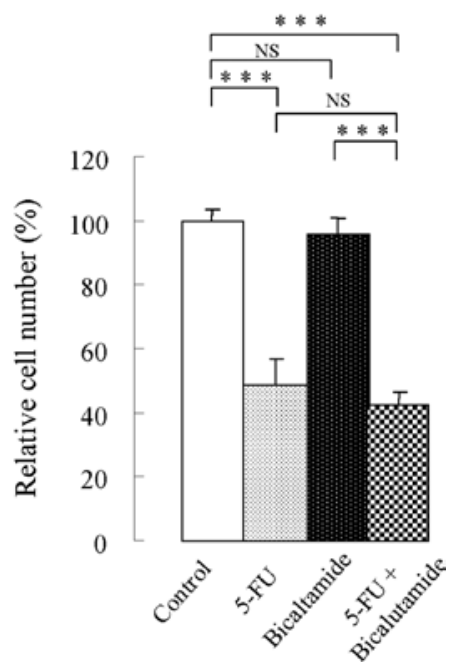

D

LNCaP

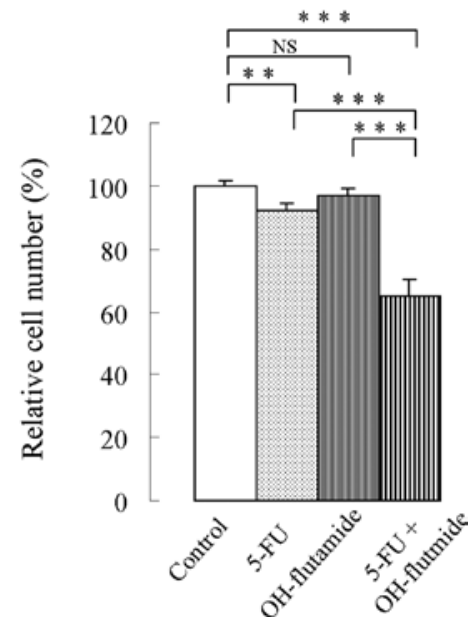

E

CDX25R

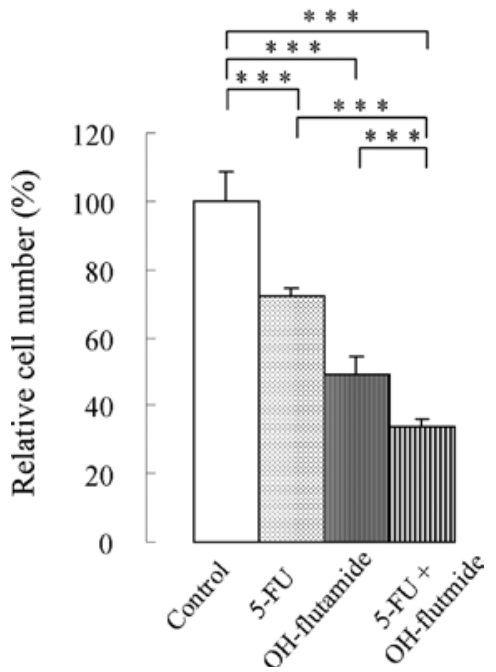

F

DU145

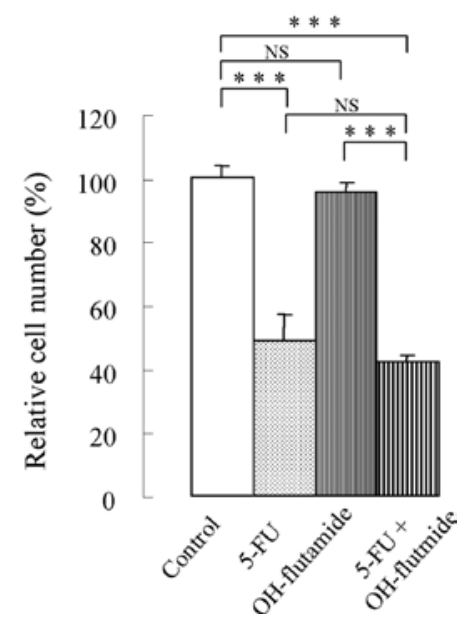

Figure 3. Combined anti-proliferative effects of 5-FU and bicalutamide or OH-flutamide in LNCaP, CDX25R and DU145 cells compared with those of the respective agents alone. Cells $\left(0.5 \times 10^{3}\right)$ were incubated in RPMI-1640 supplemented with $10 \%$ FBS for $24 \mathrm{~h}$, then treated with $3.2 \mu \mathrm{M}$ bicalutamide, $0.9 \mu \mathrm{M}$ $\mathrm{OH}$-flutamide and/or $1.6 \mu \mathrm{M}$ 5-FU for 6 days. The cell number was estimated by the crystal violet dye-uptake method, and then calculated relative to the control, which was taken as $100 \%$. Columns show the mean relative cell number, and bars represent the standard deviations (SDs). Statistical analysis was performed by the Student's t-test. Significant differences from the control are shown as ${ }^{*} p<0.05$ and ${ }^{* *} \mathrm{p}<0.01$. Experiments were repeated three times with similar results. 
Table I. 5-FU-related gene expression levels in AR-positive cells (LNCaP and CDX25R) and AR-negative cells (DU145) treated with bicalutamide or $\mathrm{OH}$-flutamide for $24 \mathrm{~h}$.

\begin{tabular}{|c|c|c|c|c|c|c|}
\hline \multirow[b]{2}{*}{ Cell line } & \multirow[b]{2}{*}{ Gene } & \multirow[b]{2}{*}{ Control } & \multicolumn{2}{|c|}{ Bicalutamide } & \multicolumn{2}{|c|}{$\mathrm{OH}$-flutamide } \\
\hline & & & $5 \mu \mathrm{M}$ & $25 \mu \mathrm{M}$ & $5 \mu \mathrm{M}$ & $25 \mu \mathrm{M}$ \\
\hline \multirow[t]{7}{*}{ LNCaP } & $\mathrm{TS}$ & $7.62 \pm 0.90$ & $5.91 \pm 0.69^{a}$ & $4.11 \pm 0.48^{b}$ & $4.01 \pm 0.56^{b}$ & $2.00 \pm 0.34^{b}$ \\
\hline & DPD & ND & ND & ND & ND & ND \\
\hline & OPRT & $6.65 \pm 0.33$ & $8.01 \pm 0.18^{b}$ & $6.08 \pm 0.80$ & $6.07 \pm 0.30$ & $2.95 \pm 0.23^{b}$ \\
\hline & $\mathrm{TP}$ & $0.50 \pm 0.02$ & $0.53 \pm 0.01$ & $0.31 \pm 0.04^{b}$ & $0.59 \pm 0.05^{\mathrm{a}}$ & $0.55 \pm 0.04$ \\
\hline & TK & $13.75 \pm 0.68$ & $17.08 \pm 0.06^{\mathrm{a}}$ & $10.99 \pm 0.04$ & $12.87 \pm 2.72$ & $5.48 \pm 0.40^{\mathrm{a}}$ \\
\hline & UP & $0.03 \pm 0.01$ & $0.04 \pm 0.01$ & $0.03 \pm 0.01$ & $0.04 \pm 0.01$ & $0.03 \pm 0.01$ \\
\hline & UK & $3.00 \pm 0.26$ & $3.31 \pm 0.31$ & $2.45 \pm 0.12^{\mathrm{a}}$ & $3.27 \pm 0.01$ & $1.80 \pm 0.13^{\mathrm{b}}$ \\
\hline \multirow[t]{7}{*}{ CDX25R } & $\mathrm{TS}$ & $8.63 \pm 0.04$ & $10.25 \pm 0.98$ & $9.55 \pm 0.74$ & $5.64 \pm 0.92^{b}$ & $3.47 \pm 0.04^{b}$ \\
\hline & DPD & ND & ND & ND & ND & ND \\
\hline & OPRT & $6.00 \pm 0.11$ & $6.54 \pm 0.83$ & $7.47 \pm 0.62$ & $4.59 \pm 0.99$ & $3.76 \pm 0.18^{b}$ \\
\hline & $\mathrm{TP}$ & $0.45 \pm 0.01$ & $0.43 \pm 0.05$ & $0.42 \pm 0.01$ & $0.44 \pm 0.04$ & $0.70 \pm 0.03^{b}$ \\
\hline & TK & $12.40 \pm 0.23$ & $13.91 \pm 1.50$ & $14.91 \pm 1.69$ & $9.69 \pm 2.54$ & $6.98 \pm 0.30^{\mathrm{b}}$ \\
\hline & UP & $0.05 \pm 0.02$ & $0.08 \pm 0.03$ & $0.09 \pm 0.04$ & $0.04 \pm 0.02$ & $0.05 \pm 0.02$ \\
\hline & UK & $2.33 \pm 0.10$ & $2.73 \pm 0.45$ & $3.18 \pm 0.27$ & $2.18 \pm 0.16$ & $2.73 \pm 0.04$ \\
\hline \multirow[t]{7}{*}{ DU145 } & $\mathrm{TS}$ & $5.36 \pm 0.43$ & $5.48 \pm 0.10$ & $5.81 \pm 0.05$ & $4.42 \pm 0.80$ & $4.58 \pm 1.08$ \\
\hline & DPD & $0.09 \pm 0.01$ & $0.10 \pm 0.01$ & $0.10 \pm 0.00$ & $0.11 \pm 0.01$ & $0.13 \pm 0.02^{\mathrm{b}}$ \\
\hline & OPRT & $1.32 \pm 0.01$ & $1.30 \pm 0.06$ & $1.45 \pm 0.03$ & $1.07 \pm 0.14$ & $1.14 \pm 0.25$ \\
\hline & $\mathrm{TP}$ & $0.31 \pm 0.01$ & $0.37 \pm 0.01$ & $0.34 \pm 0.03$ & $0.44 \pm 0.05$ & $0.44 \pm 0.13$ \\
\hline & TK & $6.55 \pm 0.06$ & $7.04 \pm 0.10$ & $7.28 \pm 0.09$ & $5.21 \pm 0.77$ & $5.05 \pm 1.95$ \\
\hline & UP & $3.07 \pm 0.38$ & $3.03 \pm 0.03$ & $3.36 \pm 0.16$ & $2.76 \pm 0.11$ & $3.82 \pm 0.25^{\mathrm{b}}$ \\
\hline & UK & $1.81 \pm 0.07$ & $3.84 \pm 2.11$ & $1.73 \pm 0.04$ & $2.01 \pm 0.04$ & $2.20 \pm 0.52$ \\
\hline
\end{tabular}

The gene expression levels were examined by real-time qRT-PCR and multiplied by $10^{2}$ to calculate the ratios to $\beta$-actin. Data shown are the mean \pm SD of one representative experiment of three. ND, not detected. Statistical analysis was performed by the Dunnett's t-test. Significant differences from the control are shown as ${ }^{\mathrm{a}} \mathrm{p}<0.05$ and ${ }^{\mathrm{b}} \mathrm{p}<0.01$. Significant changes with a dose-dependent pattern are indicated in bold.

even though the parental LNCaP cell line was OH-flutamideresistant (Fig. 3E). When CDX25R cells were co-treated with 5-FU and $\mathrm{OH}$-flutamide, the inhibitory effect of 5-FU alone $(\mathrm{T} / \mathrm{C}=72 \%)$ was significantly enhanced $(\mathrm{T} / \mathrm{C}=34 \%)$. In DU145 cells, bicalutamide and $\mathrm{OH}$-flutamide neither reduced cell growth nor affected the activity of 5-FU $(\mathrm{T} / \mathrm{C}=48.4 \%)$ (Fig. 3C and F).

mRNA expression of 5-FU-related genes with or without bicalutamide or $\mathrm{OH}$-flutamide. Initially, we examined the cytotoxicity of bicalutamide and $\mathrm{OH}$-flutamide in LNCaP and CDX25R cells. Treatment with the anti-androgens at concentrations of 25 and $50 \mu \mathrm{M}$ for 24 or $48 \mathrm{~h}$ had no antiproliferative effects, although they slightly inhibited growth at $100 \mu \mathrm{M}$ (data not shown). We then examined the mechanism underlying the synergistic growth-inhibitory activity of 5-FU and anti-androgens. Changes in the mRNA expression levels of seven factors limiting 5-FU sensitivity (TS, DPD, OPRT, TP, TK, UP and UK) were evaluated in AR-positive LNCaP and CDX25R cells, and in AR-negative DU145 cells, when treated with anti-androgens (Table I). The TS mRNA level in LNCaP cells treated with bicalut- amide or $\mathrm{OH}$-flutamide was decreased in a dose-dependent manner. The TS level in CDX25R cells was decreased by $\mathrm{OH}$-flutamide, but not bicalutamide, at a dose that was ineffective for cell viability. The TS level in DU145 cells was not decreased by bicalutamide or $\mathrm{OH}$-flutamide (Table I and Fig. 4A). The inhibition of TS by bicalutamide or $\mathrm{OH}$-flutamide appeared to depend on the sensitivity via the AR pathway.

Changes of E2F1, phosphor-retinoblastoma protein ( $p R b)$, and TS protein expression in LNCAP and CDX25R cells treated with anti-androgens. TS expression was previously reported to be regulated by E2F1 binding to an E2F1-responsive element in the promoter region of the TS gene (28-30). In addition, E2F activity was shown to be controlled by pRb family members (31). Therefore, the expression levels of TS, pRb and E2F1 protein were assessed after treatment with bicalutamide or OH-flutamide at 5, 25 or $100 \mu \mathrm{M}$ for $48 \mathrm{~h}$. Treatment with bicalutamide or $\mathrm{OH}$-flutamide clearly suppressed the protein expression levels of $\mathrm{E} 2 \mathrm{~F} 1, \mathrm{pRb}$ and $\mathrm{TS}$, with the exception of bicalutamide treatment in CDX25R cells at a dose that was ineffective for cell viability (Fig. 4B). 

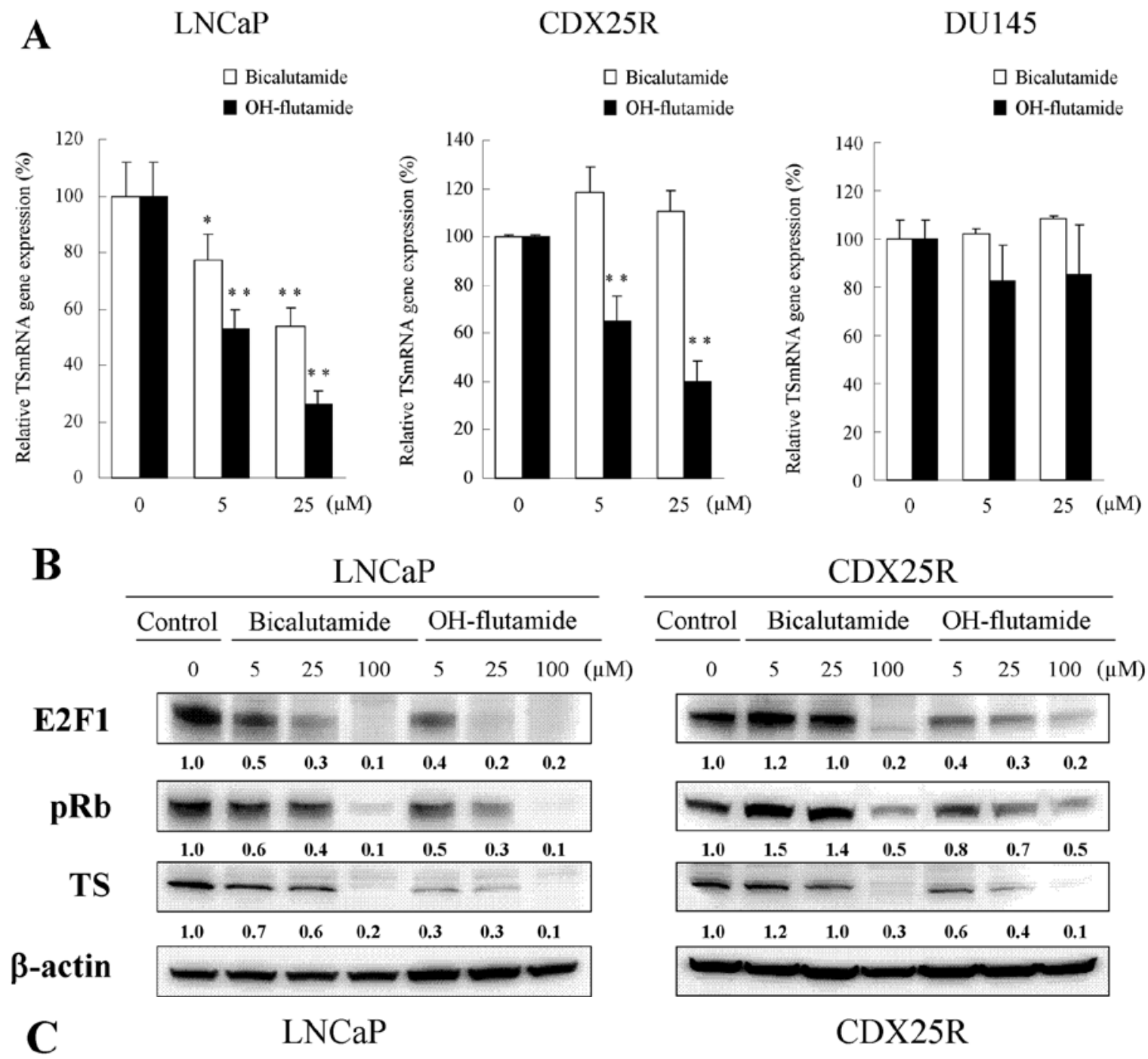

DU145

$\square$ Bicalutamide

$\square$ Bicalutamide

CDX25R

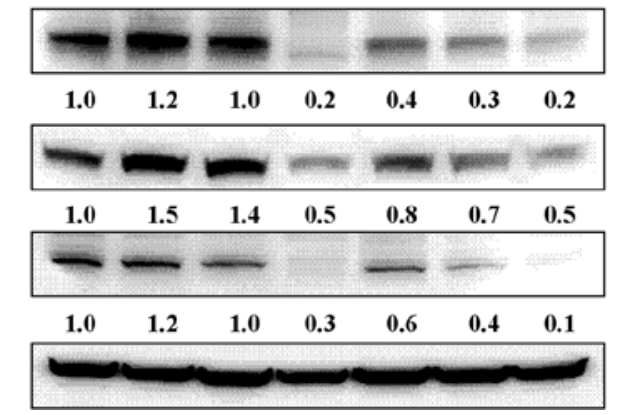

CDX25R
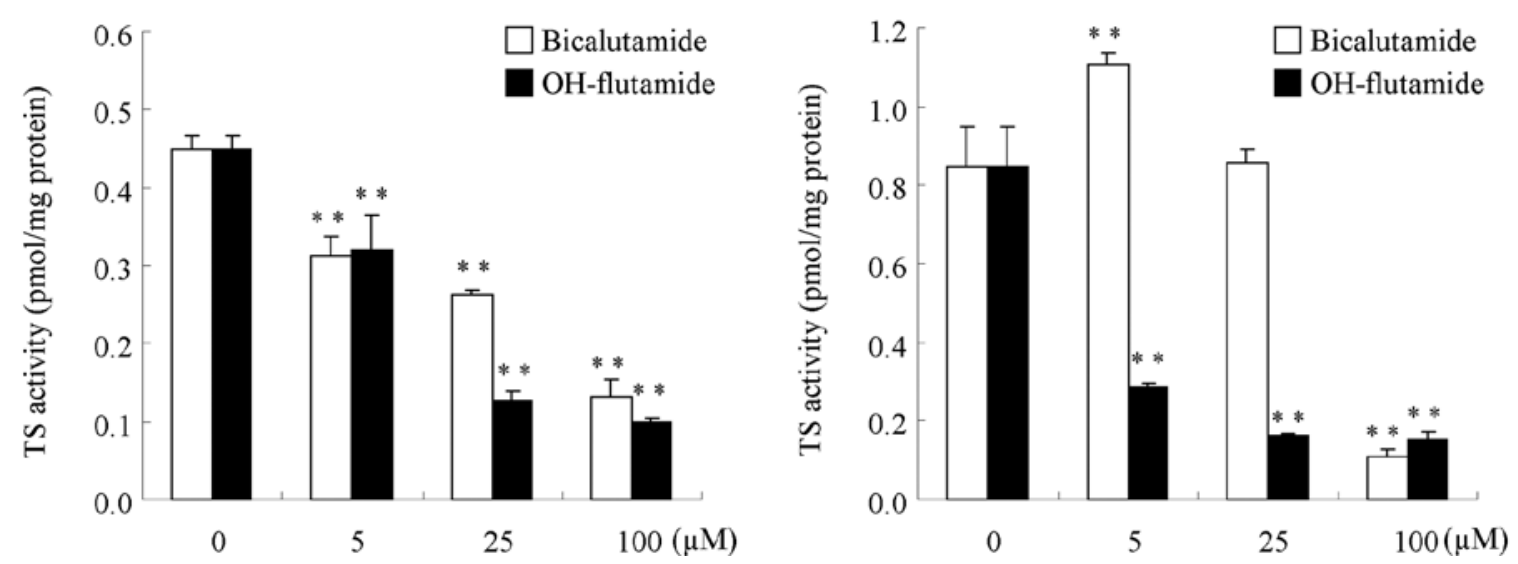

Figure 4. Suppression of TS mRNA and protein expression levels and TS activity by bicalutamide and OH-flutamide. (A) Changes of TS mRNA expression in LNCaP, CDX25R and DU145 cells treated with bicalutamide or OH-flutamide for $24 \mathrm{~h}$. The mRNA expression level was measured by real-time qRT-PCR, and the value calculated relative to that of the non-treated group, which was taken as $100 \%$. Determinations were carried out in triplicate, and bars represent SDs. Statistical analysis was carried out using the Student's t-test. Significant differences from the control are shown as *p $<0.05$ and ** $<<0.01$. (B) E2F1, $\mathrm{pRb}$ and TS protein expression levels in LNCaP and CDX25R cells treated with bicalutamide or OH-flutamide for $48 \mathrm{~h}$. The expression level was assessed by immunoblotting. Numbers below the immunoblots represent the band intensity compared with that of the corresponding loading control, $\beta$-actin. (C) TS activity in LNCaP and CDX25R cells after treatment with bicalutamide or OH-flutamide. Statistical analysis was performed using the Student's t-test. Significant differences from the control are shown as ${ }^{* *} \mathrm{p}<0.01$.

Active TS levels in cells after treatment with bicalutamide or OH-flutamide. To clarify whether the active TS level was reduced by treatment with bicalutamide or $\mathrm{OH}$-flutamide, in a similar manner to levels of mRNA and protein expression, 
A

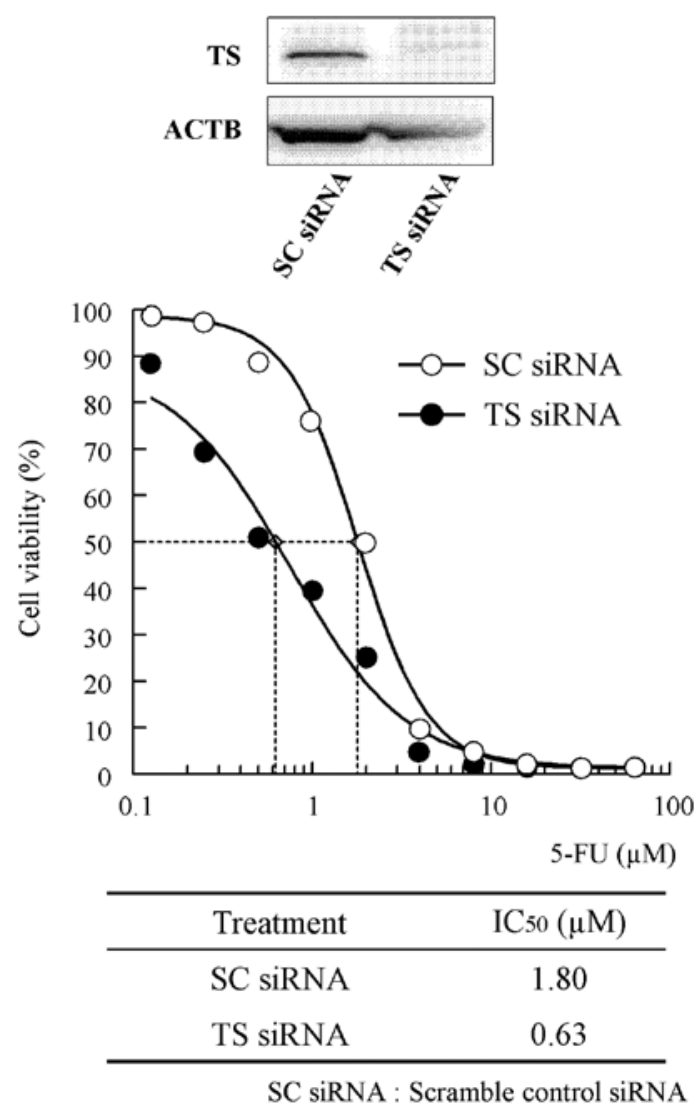

B

CDX25R

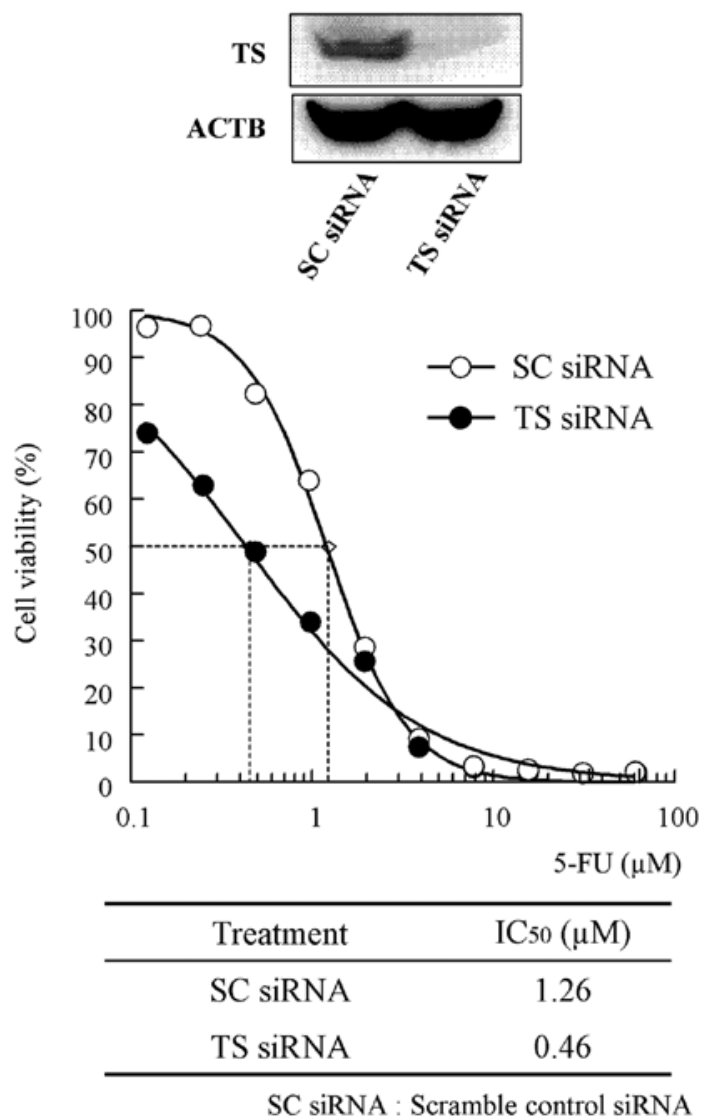

Figure 5. Effect of reduced TS expression on 5-FU sensitivity of LNCaP and CDX25R cells. TS-specific or scrambled siRNA duplexes were transfected into LNCaP and CDX25R cells. Cells were cultured in RPMI-1640 supplemented with 10\% FBS for 24 h. After adhesion, cells were grown with or without 0.125-64 $\mu \mathrm{M}$ 5-FU, with triplicate measurements, for 6 days. Cell proliferation was assayed by the crystal violet dye-uptake method. The cell proliferation relative to the control $(0 \mu \mathrm{M} 5-\mathrm{FU})$ and the $\mathrm{IC}_{50}$ value were calculated.

the free TS level was assessed using a TS binding assay method (Fig. 4C). The binding activity of TS to FdUMP in cell extracts was assessed after treatment with bicalutamide or $\mathrm{OH}$-flutamide at 5, 25 or $100 \mu \mathrm{M}$ for $48 \mathrm{~h}$. Both bicalutamide and $\mathrm{OH}$-flutamide significantly decreased the active TS levels in a dose-dependent manner, with the exception of bicalutamide treatment in CDX25R cells.

Effect of TS gene silencing on cellular sensitivity to 5-FU. To confirm whether TS limited the cellular sensitivity to 5-FU, the cytotoxic effects of 5-FU on LNCaP and CDX25R cells transfected with TS siRNA were evaluated (Fig. 5). Reducing TS expression by TS siRNA increased the cellular sensitivity to 5-FU $~ 3$-fold in LNCaP and CDX25R cells in comparison with the scrambled RNA control.

\section{Discussion}

In Japan, prostate cancer was responsible for the incidences of more than 42,000 men in 2005, and had the fourth highest morbidity rate after colorectal cancer, stomach cancer and lung cancer. In the past decade, moreover, the morbidity rate in Japan increased approximately 3.4-fold while the age-adjusted morbidity rate increased approximately 2.4-fold
(Vital Statistics Japan, Ministry of Health, Labor and Welfare; http://ganjoho.ncc.go.jp/professional/statistics/index.html).

The current study investigated the growth-inhibitory activity of anti-androgens combined with 5-FU and the mechanism underlying this combined therapy. We initially established the CDX25R cell line, which showed significant resistance to bicalutamide (Fig. 2A) and lacked androgendependency (Fig. 2C). A detailed investigation of the characteristics of CDX25R cells confirmed that endogenous AR was expressed despite the acquisition of bicalutamide resistance (Fig. 2E); however, relatively little AR was found in the nucleus and most remained in the cytoplasm after treatment with DHT (Fig. 2D). These data suggested that the androgen/AR axis in CDX25R cells might be inactivated.

Various mechanisms have been put forward to explain how prostate cancer might acquire hormone-independence, including the activation of ARs by deregulated cytokines and growth factors such as insulin-like growth factor 1 (IGF1), epidermal growth factor (EGF), keratinocyte growth factor (KGF) and interleukin-6 (IL-6), through the Janus kinase (JAK)-signal transducer and activator of transcription (STAT), Akt or mitogen-activated protein kinase (MAPK) pathways in the absence of androgen (32-39). In particular, it has been suggested that Akt might contribute to the development of 
AR-escape pathways independently of AR phosphorylation, because Akt has roles in the control of cell apoptosis and proliferation in prostate cancer cell lines, and might inhibit apoptosis by suppressing the pro-apoptotic functions of Bcl-2-associated death promoter (BAD) phosphorylation and caspase 9 (40). Akt might also signal G1 cell cycle progression by cytoplasmic mislocalization of p21 and p27, elevation of c-Myc and cyclin D and suppression of p130 (41).

We assessed the protein expression levels of some factors relating to the Akt axis, and found that p-Akt (Ser473), p-Akt (Thr308), Akt and p-PDK1 (Ser241) were significantly overexpressed compared with levels in LNCaP cells (Fig. 2E). These findings suggested that the growth of CDX25R cells might depend on hyperactivation of the Akt pathway, but not on the androgen/AR axis. Notably, CDX25R cells were highly sensitive to $\mathrm{OH}$-flutamide, unlike the parental LNCaP cell line (Fig. 3D and E). OH-flutamide does not inhibit the proliferation of LNCaP cells due to the T877A mutation of the AR gene $(42,43)$. However, the mechanism underlying the acquisition of hypersensitivity to $\mathrm{OH}$-flutamide in CDX25R cells remains to be clarified. Taken together, these results suggest that CDX25R is an AR-positive HRPC cell line that is induced to proliferate by activated Akt, regardless of the presence of androgen. The changes in sensitivity to bicalutamide and $\mathrm{OH}$-flutamide in CDX25R cells make them a good model for prostate cancer cells that have acquired resistance to firstline MAB therapy but are candidates for second-line MAB therapy with an alternative anti-androgen.

We evaluated the growth-inhibitory effects of $\mathrm{OH}$-flutamide or bicalutamide combined with 5-FU on CDX25R, LNCaP and DU145 cells (Fig. 3). Combined treatment with 5-FU and $\mathrm{OH}$-flutamide showed a synergistic growth-inhibitory effect on CDX25R cells compared with each drug administered alone (Fig. 3E). OH-flutamide did not inhibit the growth of DU145 cells because of hormone independence, and did not enhance the activity of 5-FU (Fig. 3F). LNCaP cells carry the mutation T877A of the AR gene, which prevents $\mathrm{OH}$-flutamide from inhibiting their growth. However, 5-FU and $\mathrm{OH}$-flutamide showed synergistic growth-inhibitory effects on LNCaP cells (Fig. 3D). Co-treatment with bicalutamide and 5-FU also showed synergistic anti-proliferative effects on LNCaP cells (Fig. 3A). Bicalutamide did not inhibit cell proliferation in CDX25R and DU145 cells, however, and did not enhance the activity of 5-FU (Fig. 3B and C). Overall, these results suggest that anti-androgens not only inhibit AR function but might also enhance the activity of 5-FU.

To confirm the possibility that anti-androgens enhance cellular sensitivity to 5-FU, we investigated their influence on the mRNA expression of seven enzymes that limit 5-FU activity: TS, DPD, OPRT, TP, TK, UP and UK (Table I). When the three prostate cancer cell lines were treated with bicalutamide or OH-flutamide, only the mRNA levels of TS in the AR-positive LNCaP and CDX25R cells were significantly decreased in a dose-dependent manner, with the exception of CDX25R cells treated with bicalutamide. However, TS expression in AR-negative DU145 cells was not affected by anti-androgens. We then confirmed that the down-regulation of TS using TS siRNA led to an approximately 3-fold increase in the sensitivity of LNCaP and CDX25R cells to 5-FU (Fig. 5). These results suggested that the androgen/AR axis is needed for the inhibition of TS by anti-androgens, and is correlated with cellular sensitivity to 5-FU.

Several regulating mechanisms of TS expression have been reported, including transcriptional regulation by several transcriptional factors including members of the E2F gene family $(28,31,44)$, the rTS gene system $(45-47)$ and gene amplification. We confirmed that E2F1 expression was significantly decreased in CDX25R cells treated with $\mathrm{OH}$-flutamide, whereas bicalutamide only had an effect at the lethal concentration of $100 \mu \mathrm{M}$. E2F1 expression in LNCaP cells was reduced after treatment with both $\mathrm{OH}$-flutamide and bicalutamide. These results suggested that the anti-androgen decreased the protein expression of E2F1, and subsequently the expression and activity of TS through AR, and augmented the cellular sensitivity to 5-FU.

In Japan, 5-FU is usually applied in the form of a pro-drug such as the oral anti-cancer drug UFT. This combines the DPD inhibitor uracil and tegafur, which is converted to 5-FU in the liver, at a 4:1 molecular ratio, and has been used for the treatment of colon, lung, breast, gastric and prostate cancers, among others (48-53). In patients with untreated advanced prostate cancer, combined therapy with UFT and first-line MAB was reported to be tolerable, and effectively delayed the progression to androgen-independence (54-56). At the 2010 American Society of Clinical Oncology (ASCO) annual meeting, we reported that combination therapy with UFT and second-line MAB was more effective than second-line MAB alone in a study of 53 patients with HRPC (2010 ASCO Annual Meeting abs. e15030; http://abstract.asco.org/ AbstView_74_42670.html). There were no severe adverse events in the groups treated either with MAB alone or with MAB plus UFT. The PSA response rate for combined UFT and MAB therapy $(70.6 \%)$ tended to be higher than that for second-line MAB therapy alone $(36.8 \%)(\mathrm{p}=0.054)$. Combined UFT and MAB therapy had a significantly longer median progression-free survival time (16.1 months) than that of MAB therapy alone (6.4 months) $(\mathrm{p}=0.0028)$.

To our knowledge, this is the first study to experimentally clarify the synergistic mechanism of the anti-proliferative effect of 5-FU combined with $\mathrm{OH}$-flutamide, although the clinical utility of UFT combined with MAB therapy has been reported elsewhere. Our findings suggest that $\mathrm{OH}$-flutamide or bicalutamide might induce the down-regulation of TS through AR, and augment cellular sensitivity to 5-FU in AR-positive prostate cancer cells. This mechanism might therefore exist only in AR-positive prostate cancer cells, not in AR-negative ones. For patients with untreated, AR-positive prostate cancer showing intensive androgen-dependency, firstline MAB therapy can provide sufficient clinical activity, and chemotherapy is not applied in many cases. Prostate cancer for which second-line MAB therapy is applied usually still has AR expression and is expected to be sensitive to alternative anti-androgens even though it has acquired resistance to first-line MAB.

$5-\mathrm{FU}$, especially in the form of an orally administered, low-toxicity pro-drug such as UFT, might thus be suitable for co-administration with second-line MAB therapy, owing to the synergistic mechanism demonstrated in the current report. The translation of these in vitro findings into clinical applications would have a tremendous impact on the selection of the 
best treatment modality. Practical methods for determining the down-regulation of TS, for the rational development of new regimens including anti-androgens and 5-FU, and for selecting responders to this combined therapy should be further researched.

\section{Acknowledgements}

We thank Ms. Junko Chikamoto (Tokushima Research Center, Taiho Pharmaceutical Co., Ltd.) for technical assistance, Dr Masakazu Fukushima (Tokushima Research Center, Taiho Pharmaceutical Co., Ltd.) and Dr Kiyoshi Eshima (The University of Tokushima, Japan) for fruitful discussions.

\section{References}

1. Prostate Cancer Trialists' Collaborative Group: Maximum androgen blockade in advanced prostate cancer: an overview of the randomised trials. Lancet 355: 1491-1498, 2000.

2. Schmitt B, Wilt TJ, Schellhammer PF, et al: Combined androgen blockade with nonsteroidal antiandrogens for advanced prostate cancer: a systematic review. Urology 57: 727-732, 2001.

3. Oh WK and Kantoff PW: Management of hormone refractory prostate cancer: current standards and future prospects. J Uro 160: 1220-1229, 1998.

4. Kojima S, Suzuki H, Akakura K, Shimbo M, Ichikawa T and Ito $\mathrm{H}$ : Alternative antiandrogens to treat prostate cancer relapse after initial hormone therapy. J Urol 171: 679-683, 2004.

5. Miyake H, Hara I and Eto H: Clinical outcome of maximum androgen blockade using flutamide as second-line hormonal therapy for hormone-refractory prostate cancer. BJU Int 96: 791-795, 2005.

6. Nishimura K, Arichi N, Tokugawa S, Yoshioka I, Kishikawa H and Ichikawa Y: Effects of flutamide as a second-line agent for maximum androgen blockade of hormone refractory prostate cancer. Int J Urol 14: 264-267, 2007.

7. Gulley J, Figg WD and Dahut WL: Treatment options for androgen-independent prostate cancer. Clin Adv Hematol Oncol 1: 49-57, 2003.

8. Lara PN Jr and Meyers FJ: Treatment options in androgenindependent prostate cancer. Cancer Invest 17: 137-144, 1999.

9. Tannock IF, de Wit R, Berry WR, et al: Docetaxel plus prednisone or mitoxantrone plus prednisone for advanced prostate cancer. N Engl J Med 351: 1502-1512, 2004.

10. Petrylak DP, Tangen CM, Hussain MH, et al: Docetaxel and estramustine compared with mitoxantrone and prednisone for advanced refractory prostate cancer. N Engl J Med 351: 1513-1520, 2004.

11. Meyers M, Hwang A, Wagner MW, et al: A role for DNA mismatch repair in sensing and responding to fluoropyrimidine damage. Oncogene 22: 7376-7388, 2003.

12. Salonga D, Danenberg KD, Johnson M, et al: Colorectal tumors responding to 5-fluorouracil have low gene expression levels of dihydropyrimidine dehydrogenase, thymidylate synthase, and thymidine phosphorylase. Clin Cancer Res 6: 1322-1327, 2000.

13. Lurje G, Manegold PC, Ning Y, Pohl A, Zhang W and Lenz HJ: Thymidylate synthase gene variations: predictive and prognostic markers. Mol Cancer Ther 8: 1000-1007, 2009.

14. Ikeguchi M, Makino M and Kaibara N: Thymidine phosphorylase and dihydropyrimidine dehydrogenase activity in colorectal carcinoma and patients prognosis. Langenbecks Arch Surg 387: 240-245, 2002

15. Carreras CW and Santi DV: The catalytic mechanism and structure of thymidylate synthase. Annu Rev Biochem 64: 721-762, 1995.

16. Costi MP, Ferrari S, Venturelli A, Calo S, Tondi D and Barlocco D: Thymidylate synthase structure, function and implication in drug discovery. Curr Med Chem 12: 2241-2258, 2005.

17. Johnston PG, Lenz HJ, Leichman CG, et al: Thymidylate synthase gene and protein expression correlate and are associated with response to 5-fluorouracil in human colorectal and gastric tumors. Cancer Res 55: 1407-1412, 1995.
18. Miyoshi $\mathrm{Y}$, Uemura $\mathrm{H}$, Ishiguro $\mathrm{H}$, et al: Expression of thymidylate synthase, dihydropyrimidine dehydrogenase, thymidine phosphorylase, and orotate phosphoribosyl transferase in prostate cancer. Prostate Cancer Prostatic Dis 8: 260-265, 2005.

19. Mizutani Y, Wada H, Yoshida O, et al: Significance of thymidylate synthase activity in renal cell carcinoma. Clin Cancer Res 9: 1453-1460, 2003.

20. Nomura T, Nakagawa M, Fujita Y, Hanada T, Mimata H and Nomura Y: Clinical significance of thymidylate synthase expression in bladder cancer. Int J Urol 9: 368-376, 2002.

21. Pestalozzi BC, Peterson HF, Gelber RD, et al: Prognostic importance of thymidylate synthase expression in early breast cancer. J Clin Oncol 15: 1923-1931, 1997.

22. Shintani Y, Ohta M, Hirabayashi $\mathrm{H}$, et al: New prognostic indicator for non-small-cell lung cancer, quantitation of thymidylate synthase by real-time reverse transcription polymerase chain reaction. Int J Cancer 104: 790-795, 2003.

23. Suzuki M, Tsukagoshi S, Saga Y, Ohwada M and Sato I: Enhanced expression of thymidylate synthase may be of prognostic importance in advanced cervical cancer. Oncology 57: 50-54, 1999.

24. Li Y, Mizutani Y, Shiraishi T, et al: Prognostic significance of thymidylate synthase expression in patients with prostate cancer undergoing radical prostatectomy. Urology 69: 988-995, 2007.

25. Edler D, Hallstrom M, Johnston PG, Magnusson I, Ragnhammar P and Blomgren $\mathrm{H}$ : Thymidylate synthase expression: an independent prognostic factor for local recurrence, distant metastasis, disease-free and overall survival in rectal cancer. Clin Cancer Res 6: 1378-1384, 2000.

26. Saotome K, Morita H and Umeda M: Cytotoxicity test with simplified crystal violet staining method using microtitre plates and its application to injection drugs. Toxicol In Vitro 3: 317-321, 1989.

27. Spears CP, Shahinian AH, Moran RG, Heidelberger C and Corbett TH: In vivo kinetics of thymidylate synthetase inhibition of 5-fluorouracil-sensitive and -resistant murine colon adenocarcinomas. Cancer Res 42: 450-456, 1982.

28. DeGregori J, Kowalik T and Nevins JR: Cellular targets for activation by the E2F1 transcription factor include DNA synthesis- and G1/S-regulatory genes. Mol Cell Biol 15: 4215-4224, 1995

29. Dong S, Lester L and Johnson LF: Transcriptional control elements and complex initiation pattern of the TATA-less bidirectional human thymidylate synthase promoter. J Cell Biochem 77: $50-64,2000$.

30. Helin K: Regulation of cell proliferation by the E2F transcription factors. Curr Opin Genet Dev 8: 28-35, 1998.

31. Dyson N: The regulation of E2F by pRB-family proteins. Genes Dev 12: 2245-2262, 1998

32. Gregory CW, Whang YE, McCall W, et al: Heregulin-induced activation of HER 2 and HER 3 increases androgen receptor transactivation and CWR-R1 human recurrent prostate cancer cell growth. Clin Cancer Res 11: 1704-1712, 2005.

33. Chen T, Wang LH and Farrar WL: Interleukin 6 activates androgen receptor-mediated gene expression through a signal transducer and activator of transcription 3-dependent pathway in LNCaP prostate cancer cells. Cancer Res 60: 2132-2135, 2000.

34. Lee SO, Lou W, Hou M, de Miguel F, Gerber L and Gao AC: Interleukin-6 promotes androgen-independent growth in $\mathrm{LNCaP}$ human prostate cancer cells. Clin Cancer Res 9: 370-376, 2003.

35. Malinowska K, Neuwirt H, Cavarretta IT, et al: Interleukin-6 stimulation of growth of prostate cancer in vitro and in vivo through activation of the androgen receptor. Endocr Relat Cancer 16: 155-169, 2009.

36. Wen Y, Hu MC, Makino K, et al: HER-2/neu promotes androgen-independent survival and growth of prostate cancer cells through the Akt pathway. Cancer Res 60: 6841-6845, 2000.

37. Murillo H, Huang H, Schmidt LJ, Smith DI and Tindall DJ: Role of PI3K signaling in survival and progression of $\mathrm{LNCaP}$ prostate cancer cells to the androgen refractory state. Endocrinology 142: 4795-4805, 2001.

38. Gao N, Zhang Z, Jiang BH and Shi X: Role of PI3K/AKT/mTOR signaling in the cell cycle progression of human prostate cancer. Biochem Biophys Res Commun 310: 1124-1132, 2003.

39. Pfeil K, Eder IE, Putz T, et al: Long-term androgen-ablation causes increased resistance to PI3K/Akt pathway inhibition in prostate cancer cells. Prostate 58: 259-268, 2004.

40. Sun M, Yang L, Feldman RI, et al: Activation of phosphatidylinositol 3-kinase/Akt pathway by androgen through interaction of p85alpha, androgen receptor, and Src. J Biol Chem 278: 42992-43000, 2003. 
41. Liang J and Slingerland JM: Multiple roles of the PI3K/PKB (Akt) pathway in cell cycle progression. Cell Cycle 2: 339-345, 2003.

42. Veldscholte J, Ris-Stalpers C, Kuiper GG, et al: A mutation in the ligand binding domain of the androgen receptor of human LNCaP cells affects steroid binding characteristics and response to anti-androgens. Biochem Biophys Res Commun 173: 534-540, 1990.

43. Steketee K, Timmerman L, Ziel-van der Made AC, Doesburg P, Brinkmann AO and Trapman J: Broadened ligand responsiveness of androgen receptor mutants obtained by random amino acid substitution of $\mathrm{H} 874$ and mutation hot spot T877 in prostate cancer. Int J Cancer 100: 309-317, 2002.

44. Trimarchi JM and Lees JA: Sibling rivalry in the E2F family. Nat Rev Mol Cell Biol 3: 11-20, 2002.

45. Dolnick BJ: Cloning and characterization of a naturally occurring antisense RNA to human thymidylate synthase mRNA. Nucleic Acids Res 21: 1747-1752, 1993.

46. Dolnick BJ, Black AR, Winkler PM, Schindler K and Hsueh CT: rTS gene expression is associated with altered cell sensitivity to thymidylate synthase inhibitors. Adv Enzyme Regul 36: 165-180, 1996.

47. Dolnick BJ, Angelino NJ, Dolnick R and Sufrin JR: A novel function for the rTS gene. Cancer Biol Ther 2: 364-369, 2003.

48. Kato $\mathrm{H}$, Ichinose $\mathrm{Y}$, Ohta $\mathrm{M}$, et al: A randomized trial of adjuvant chemotherapy with uracil-tegafur for adenocarcinoma of the lung. N Engl J Med 350: 1713-1721, 2004.

49. Kasumi F, Yoshimoto M, Uchino J, et al: Meta-analysis of five studies on tegafur plus uracil (UFT) as post-operative adjuvant chemotherapy for breast cancer. Oncology 64: 146-153, 2003.
50. Taguchi T: Clinical application of biochemical modulation in cancer chemotherapy: biochemical modulation for 5-FU. Oncology 54 (Suppl. 1): S12-S18, 1997.

51. Tanaka F: UFT (tegafur and uracil) as postoperative adjuvant chemotherapy for solid tumors (carcinoma of the lung, stomach, colon/rectum, and breast): clinical evidence, mechanism of action, and future direction. Surg Today 37: 923-943, 2007.

52. Bhandari MS, Pienta KJ, Fardig J, Olson K and Smith DC: Phase II trial of oral uracil/tegafur plus leucovorin in patients with hormone-refractory prostate carcinoma. Cancer 106: 1715-1721, 2006.

53. Miyake H, Hara I, Yamazaki H and Eto H: Clinical outcome of oral uracil/tegafur (UFT) therapy for patients with hormone refractory prostate cancer. Oncol Rep 14: 673-676, 2005.

54. Kuriyama M, Takahashi Y, Sahashi M, et al: Prospective and randomized comparison of combined androgen blockade versus combination with oral UFT as an initial treatment for prostate cancer. Jpn J Clin Oncol 31: 18-24, 2001.

55. Sakai H, Minami Y, Kanetake H and Saito Y: Chemo-endocrine therapy for prostate cancer with bone metastasis. Nagasaki Prostate Cancer Research Group. Cancer Chemother Pharmacol 35 (Suppl.): S23-S26, 1994.

56. Sumiyoshi Y, Hashine K, Kuwahara M, et al: [Primary treatment for stage D2 prostate cancer: a randomized study of combined androgen blockade alone versus combined with UFT]. Gan To Kagaku Ryoho 26: 1153-1158, 1999. 